\title{
Minimum effective dose of chenic acid for gallstone patients: reduction with bedtime administration and a low cholesterol diet
}

\author{
D P MAUDGAL, R M KUPFER, AND T C NORTHFIELD*
}

From the Norman Tanner Gastroenterology Unit, St. James's Hospital and Department of Medicine, St. George's Hospital Medical School, London

SUMMARY The aim of this study was to determine whether bedtime administration and a low cholesterol diet reduce the minimum effective dose of chenodeoxycholic (chenic) acid, defined as the dose giving a mean cholesterol saturation index of $0 \cdot 8$. Dose response studies were carried out in 10 patients with radiolucent gallstones in a functioning gallbladder during three different treatment regimens. On each regimen, all patients received three different doses of chenodeoxycholic acid in random order for one month each. Bedtime chenic acid plus a low cholesterol diet gave the greatest reduction in saturation index. A significant dose/response relationship was found on each regimen. On the conventional regimen of mealtime chenic acid, the minimum effective dose was $14 \mathrm{mg} / \mathrm{kg} / \mathrm{day}$; on bedtime chenic acid it was $12.4 \mathrm{mg} / \mathrm{kg} / \mathrm{day}$; and on bedtime chenic acid plus low cholesterol diet it was further reduced to $8.4 \mathrm{mg} / \mathrm{kg} / \mathrm{day}(\mathrm{P}<0.01)$. There was a dose-related increase in bowel frequency, which was absent at $10.6 \mathrm{mg} / \mathrm{kg} / \mathrm{day}$ and below. We conclude that administration of chenic acid at bedtime with a low cholesterol diet enables the minimum effective dose for gallstone dissolution to be approximately halved, thus preventing diarrhoea and reducing the cost of treatment.

Oral administration of chenodeoxycholic (chenic) acid to cholesterol gallstone patients reduces cholesterol saturation index of fasting gallbladder bile and induces gallstone dissolution. ${ }^{1-4} \mathrm{~A}$ mean saturation index of 0.8 is associated with consistent dissolution of radiolucent gallstones. ${ }^{5}$ When chenic acid is taken in the conventional manner at mealtimes, reduction in mean saturation index to $0 \cdot 8$ has been reported with the currently recommended dose of $14-15 \mathrm{mg} / \mathrm{kg} /$ day. ${ }^{5}$ With the alternative bile acid, ursodeoxycholic acid, an equal effect has been achieved with the lower dose of $9.7 \mathrm{mg} / \mathrm{kg} / \mathrm{day} .^{6}$

We have previously shown that the effect of chenic acid $(15 \mathrm{mg} / \mathrm{kg} / \mathrm{day})$ on saturation index of fasting gallbladder bile is enhanced by bedtime administration ${ }^{7}$ and by a low cholesterol diet. ${ }^{8}$ The aim of the present study was to assess the effect of these two therapeutic measures on the minimum effective dose of chenic acid, defined as the dose giving mean

\footnotetext{
*Address for reprint requests: Dr T C Northfield, Department of Medicine, St. George's Hospital Medical School, Cranmer Terrace, London SW17 0RE, England.

Received for publication 1 September 1981
}

saturation index of $0 \cdot 8$, in a different group of patients to that previously reported. ${ }^{78} \mathrm{~A}$ reduction in minimum effective dose would be expected to reduce dose-related diarrhoea, ${ }^{1349}$ as well as the cost of treatment. We have therefore carried out dose response studies in 10 gallstone patients on three separate treatment regimens (mealtime chenic acid, bedtime chenic acid, and bedtime chenic acid plus low cholesterol diet).

\section{Methods}

\section{PATIENTS}

Ten patients (four men and six women) with radiolucent gallstones in gallbladders that opacified during oral cholecystogram were studied. All patients had normal liver function tests (bilirubin, SGOT, SGPT, alkaline phosphatase, and serum albumin). Details of patients are given in the Table. Percentage ideal body weight was $106 \cdot 7 \pm 3 \cdot 0$ (mean \pm SEM) in the 10 patients participating in regimens $A$ and $B$ and in the six patients participating in regimen $C$ it was $104 \cdot 2 \pm 3.9 \%$. Throughout the 
Table Details of individual patients

\begin{tabular}{|c|c|c|c|c|c|}
\hline Sex & $\begin{array}{l}\text { Age } \\
(y r)\end{array}$ & $\begin{array}{l}W t \\
(\mathbf{k g})\end{array}$ & $\begin{array}{l}\% \\
I B W\end{array}$ & $\begin{array}{l}\text { Initial } \\
\text { SI }\end{array}$ & $\begin{array}{l}\text { Treatment } \\
\text { regimen } \\
\text { order }\end{array}$ \\
\hline $\begin{array}{l}\mathbf{F} \\
\mathbf{M} \\
\mathbf{F} \\
\mathbf{M} \\
\mathbf{F} \\
\mathbf{M} \\
\mathbf{M} \\
\mathbf{F} \\
\mathbf{F} \\
\mathbf{F}\end{array}$ & $\begin{array}{l}73 \\
52 \\
55 \\
66 \\
35 \\
69 \\
35 \\
65 \\
55 \\
62\end{array}$ & $\begin{array}{l}65 \\
89 \\
62 \\
70 \\
59 \\
64 \\
63 \\
71 \\
69 \\
75\end{array}$ & $\begin{array}{r}100 \\
121 \\
101 \\
100 \\
109 \\
94 \\
98 \\
110 \\
114 \\
120\end{array}$ & $\begin{array}{l}1.67 \\
2.01 \\
1.23 \\
1.57 \\
1.23 \\
1.07 \\
0.77 \\
1.15 \\
1.22 \\
0.91\end{array}$ & $\begin{array}{l}\text { ABC } \\
\text { BAC } \\
\text { ABC } \\
\text { BAC } \\
\text { ABC } \\
\text { BAC } \\
\text { AB } \\
\text { BA } \\
\text { AB } \\
\text { BA }\end{array}$ \\
\hline Mean & 56.7 & $68 \cdot 2$ & $106 \cdot 7$ & 1.28 & \\
\hline
\end{tabular}

IBW: ideal body weight.

SI: saturation index.

study period, the maximum change in weight in any individual patient was less than $5 \%$ of initial body weight. Written informed consent was obtained from each patient before entering these studies, which were approved by the local hospital ethical committee.

\section{EXPERIMENTAL DESIGN}

All 10 patients received regimen $A$ which consisted of a low cholesterol diet $(100 \mathrm{mg} /$ day $)$ as described previously ${ }^{8}$ plus bedtime chenic acid given in three different doses $(250,500$, and $750 \mathrm{mg}$ daily) for one month each in random order; and regimen $B$, which consisted of a normal cholesterol $\operatorname{diet}^{8}(600 \mathrm{mg} /$ day $)$ plus bedtime chenic acid in the same doses as for regimen $\mathrm{A}$. Five of the 10 patients were randomly allocated to start on regimen $A$, and the other five to start on regimen $B$. At the end of three months, patients finishing regimen $A$ crossed over to regimen $B$ and vice versa, so that at six months all 10 patients had been studied on both regimens. At this stage six patients (three from each group) were studied on regimen $C$ (the conventional regimen, which consisted of a normal cholesterol diet with chenic acid given in three divided doses at mealtimes). On this regimen, chenic acid was given in doses of 375,750 , and $1125 \mathrm{mg}$ daily.

On all three treatment regimens, all three different doses of chenic acid were given for one month each in random order. At the end of each month, fasting gallbladder bile was obtained by nasoduodenal intubation and intravenous infusion of cholecystokinin (Boots Ltd) dissolved in normal saline. At each monthly visit, daily bowel frequency during the previous week was recorded.

At each monthly visit, the patients were also seen by a professional dietician. At the first visit, the patients were given a sample menu, already published. ${ }^{8}$ For the cholesterol-containing items (meat, eggs, and milk) a list of alternative items containing the same amount of cholesterol was also given to the patients to ensure variety. At subsequent visits, the dietician questioned the patients about compliance, and discussed problems or queries that had arisen. Patients were also encouraged to telephone the dietician to discuss problems as soon as they arose between visits. Bile sampling during chenic acid treatment was not started until the dietician was satisfied that the patient had stuck carefully to the diet for at least one month.

Statistical comparisons between different treatment regimens were based on the paired $t$ test, and analysis of covariance.

BILE ANALYSIS

All bile samples from each patient were analysed in one batch at the end of the experiment. Total bile acid concentration was measured by $3 \alpha$-hydroxysteroid dehydrogenase enzyme assay. ${ }^{10} 11$ Phospholipids were measured by the method of Bartlett, ${ }^{12}$ and cholesterol was measured by the cholesterol oxidase method $^{13}$ in an aliquot of bile diluted at the bedside in isopropanol. Cholesterol saturation index was calculated using the polynomial equation developed by Thomas and Hofmann, ${ }^{14}$ based on the limits of cholesterol solubility described by Hegardt and Dam ${ }^{15}$ and Holzbach et al. ${ }^{16}$

\section{Results}

\section{SATURATION INDEX OF FASTING GALLBLADDER} BILE

On all three treatment regimens there was a significant correlation between saturation index and dose of chenic acid (mg/kg/day). If the pretreatment saturation index is taken into account (Figs. 1 and 2), for regimen $A$ (bedtime chenic acid plus low cholesterol diet) $r=-0.45, \mathrm{P}<0.01$; for regimen $\mathrm{B}$ (bedtime chenic acid plus normal cholesterol diet) $r=-0.52, \mathrm{P}<0.01$; for regimen $\mathrm{C}$ (mealtime chenic acid plus a normal cholesterol diet) $r=-0.68$, $\mathbf{P}<0.01$. Minimum effective dose on the conventional regimen (C) was $14.0 \mathrm{mg} / \mathrm{kg} /$ day (Fig. 1). On bedtime chenic acid (regimen B) it was $12.4 \mathrm{mg} / \mathrm{kg} /$ day, and on bedtime chenic acid plus low cholesterol diet (regimen A) it fell to $8.4 \mathrm{mg} / \mathrm{kg} /$ day (Fig. 2). There was a significant difference in intercept between the two regression lines $(P<0.01)$.

If the pretreatment saturation index is excluded, there still remains a significant correlation between the saturation index and dose of chenic acid on regimens $A$ and $C$ (on regimen $A, r=-0.45, P<0.02$; on regimen $\mathrm{C}, \quad r=-0.47, \quad \mathrm{P}<0.05)$. Minimum effective dose calculated from these regression lines was 8.3 and $14.0 \mathrm{mg} / \mathrm{kg} /$ day on regimens $A$ and $C$ respectively. 


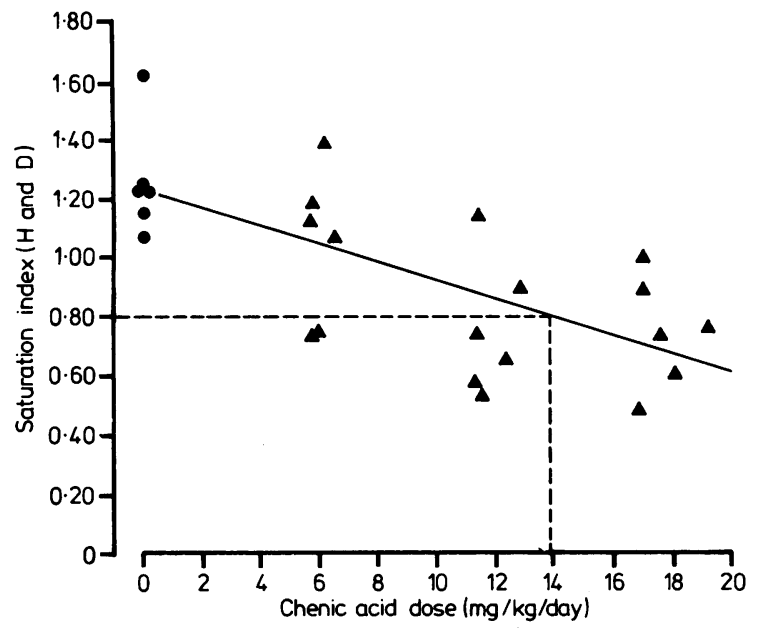

Fig. 1 Dose/response relationship on conventional regimen (regimen C: mealtime chenic acid plus normal cholesterol diet). $\Delta$ Normal cholesterol diet. Pre-treatment. $n=24$, $r=-0.68, \mathrm{P}<0.001$.

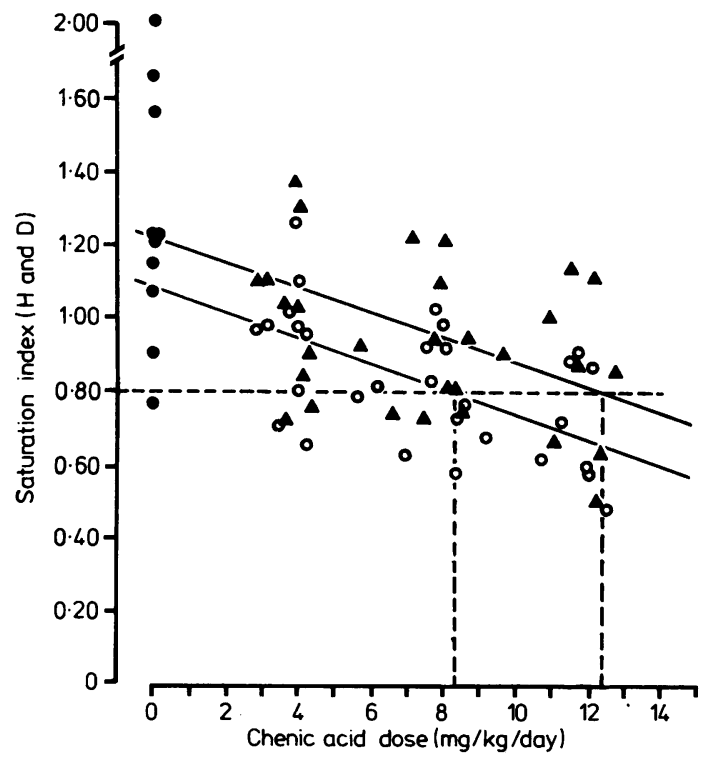

Fig. 2 Dose/response relationship on regimen A (bedtime chenic acid plus low cholesterol diet) and regimen $B$ (bedtime chenic acid plus normal cholesterol diet). $O$ Pre-treatment. $\Delta$ Normal cholesterol diet $r=-0.52, \mathrm{P}<0.01 . \bigcirc$ Low cholesterol diet $r=-0.45, \mathrm{P}<0.01$.

In Fig. 3, saturation index for individual subjects has been plotted for the three doses studied $(250$, 500 , and $750 \mathrm{mg}$ daily) on regimen A and regimen B. At a dose of $750 \mathrm{mg}$ daily on regimen $A$ all 10 patients had a saturation index of less than 1 and seven of the

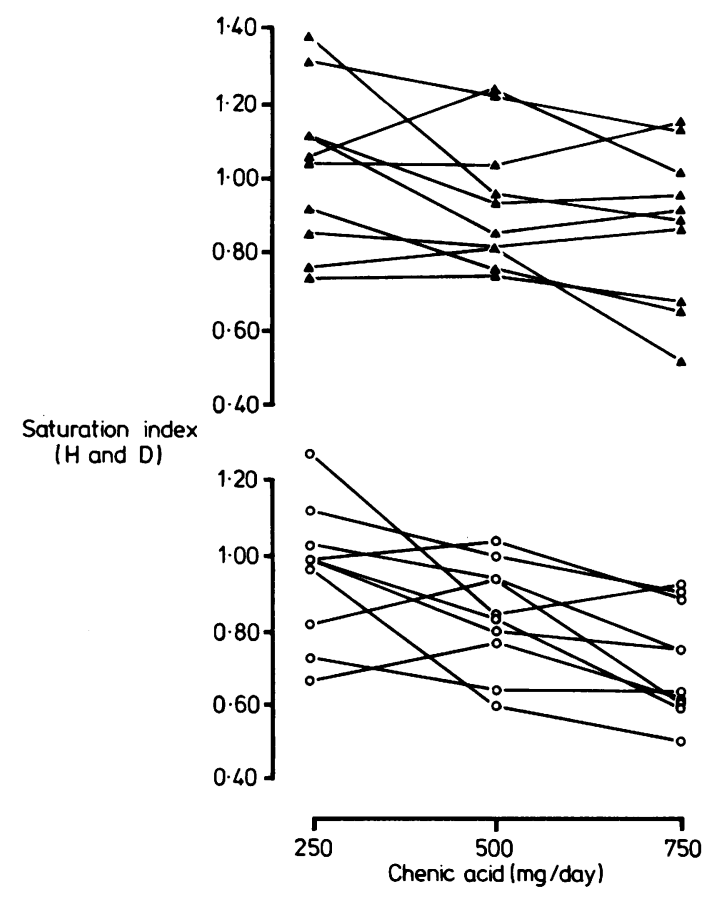

Fig. 3 Dose/response relationship in individual subjects on regimen $A$ (bedtime chenic acid plus low cholesterol diet: $\bigcirc$ ) and on regimen $B$ (bedtime chenic acid plus normal cholesterol diet: $\mathbf{\Delta})$.

patients had a saturation index of less than $0 \cdot 8$. At the same dose, on regimen $B$, only seven of the 10 patients had a saturation index of less than 1 and only three a saturation index of less than $0 \cdot 8$. On regimen $A$ and regimen $B$ respectively, saturation index (mean \pm SEM) was $0.94 \pm 0.05$ and $1.02 \pm 0.06$ on 250 $\mathrm{mg}$ daily $(\mathrm{P}<0.01), 0.83 \pm 0.04$ and $0.92 \pm 0.06$ on 500 $\mathrm{mg}$ daily $(\mathrm{P}<0.05)$, and $0.71 \pm 0.04$ and $0.86 \pm 0.06$ on $750 \mathrm{mg}$ daily $(\mathrm{P}<0 \cdot 01)$.

\section{BOWEL FREQUENCY}

Pretreatment bowel frequency (mean \pm SEM) was $0 \cdot 8 \pm 0 \cdot 1$ motions daily. On mealtime chenic acid (regimen C) it was $0 \cdot 9 \pm 0 \cdot 1$ on $375 \mathrm{mg}$ daily and $1 \cdot 1 \pm 0 \cdot 1 \mathrm{on} 750 \mathrm{mg}$ daily, but rose to $1 \cdot 8 \pm 0 \cdot 3$ on 1125 $\mathrm{mg}$ daily $(\mathrm{P}<0.02)$. The highest dose for bedtime chenic acid plus low cholesterol diet (regimen A) was $750 \mathrm{mg}$ daily, and this gave the same bowel frequency $(1 \cdot 1 \pm 0 \cdot 1)$ as mealtime chenic acid.

\section{Discussion}

In defining our minimum effective dose for a group of gallstone patients as the dose giving a mean saturation index of 0.8 we have used the same criteria 
as those given for recommended dose by Dowling and colleagues. ${ }^{5}$ They based this recommendation on the finding that a mean saturation index of 0.8 was associated with consistent gallstone dissolution ${ }^{5}$ and was achieved using a mean dose of $14.4 \mathrm{mg} / \mathrm{kg} /$ day. They carried out a dose response study ${ }^{9}$ for chenic acid, and a mean saturation index of 0.8 was again achieved with an average dose of $14-15 \mathrm{mg} / \mathrm{kg} /$ day. Like them we included pretreatment saturation index. If this is excluded, a significant dose response relationship is still found for our data, and the values for minimum effective dose are virtually unchanged.

Our experimental design was of necessity a complicated one, because we wished to study three different treatment regimens, three different doses of chenic acid being given for one month each on all three regimens. We realised that not all patients would complete the full nine months' study, which involved a total of 10 intubations. Our first priority was to determine minimum effective dose on bedtime chenic acid taken both with and without a low cholesterol diet. All 10 patients participated in these two regimens in random order. Minimum effective dose was $12.4 \mathrm{mg} / \mathrm{kg} /$ day with bedtime administration of chenic acid and a normal cholesterol diet (Fig. 2). The addition of a low cholesterol diet to bedtime chenic acid administration enhanced the effect of chenic acid at all doses studied, and significantly altered the regression line defining the dose response relationship. It further reduced minimum effective dose to $8.4 \mathrm{mg} / \mathrm{kg} / \mathrm{day}$. On this dose, only one patient had super-saturated bile (saturation index 1.03).

Our second priority was to confirm that our results on the conventional regimen of mealtime chenic acid and normal cholesterol diet were similar to those of other groups. Six of the 10 patients who had already participated in the other two dose response studies agreed to take part in this third dose response study. These six patients did not differ from the others in terms of weight, percentage ideal body weight, and age (Table). There were three men and three women, compared with four men and six women. As all doses of chenic acid were given for one month, an order effect would not have been expected but, if present, it would have tended to minimise any difference between this and the other two regimens. The minimum effective dose obtained, $14.0 \mathrm{mg} / \mathrm{kg} /$ day, was very similar to the value of $14.4 \mathrm{mg} / \mathrm{kg} / \mathrm{day}$ reported by Iser $e t$ al. to give a mean saturation index of $0 \cdot 8 .^{5}$

The low cholesterol diet proved much more acceptable to the patients than a low calorie diet and many of the patients continued on it for preference after the studies had been completed. The main principles of the diet were to use margarine instead of butter, to eat only lean meat with the fat removed, to drink only skimmed milk, and to avoid eggs completely.

Increased bowel frequency is a troublesome side-effect of chenic acid. It can be avoided if a low enough dose is given, as this effect is well known to be dose-related. ${ }^{1349}$ In the current study, daily bowel frequency remained unchanged on 375 and 750 $\mathrm{mg}$ chenic acid daily $(5.5$ and $11 \mathrm{mg} / \mathrm{kg} /$ day), but increased significantly on $1125 \mathrm{mg}$ daily $(16.5$ $\mathrm{mg} / \mathrm{kg} /$ day). As reported in a previous study ${ }^{7}$ a single bedtime dose of chenic acid did not increase bowel frequency when compared with mealtime administration of the same total daily dose of chenic acid. Thus, administration of chenic acid at bedtime with a low cholesterol diet enables the minimum effective dose for gallstone dissolution to be approximately halved, thus preventing diarrhoea and reducing the cost of treatment.

We are grateful to Weddel Pharmaceuticals for financial support, Mrs Moya Gannon for nursing assistance, and Mr R Bird for technical assistance.

\section{References}

1 Danzinger RG, Hofmann AF, Schoenfield LJ et al. Dissolution of cholesterol gallstones by chenodeoxycholic acid. $N$ Engl J Med 1972; 286:1-8.

2 Bell GD, Whitney B, Dowling RH. Gallstone dissolution in man using chenodeoxycholic acid. Lancet 1972; 11:1213-6.

3 Thistle JL, Hofmann AF. Efficacy and specificity of chenodeoxycholic acid therapy for dissolving gallstones. $N$ Engl J Med 1973; 289:655-9.

4 James O, Cullen J, Bouchier IAD. Chenodeoxycholic acid therapy for gallstones. Effectiveness, toxicity and influence on bile acid metabolism. $Q J$ Med 1975; 44:349-57.

5 Iser JH, Dowling RH, Mok HYI et al. Chenodeoxycholic acid treatment of gallstones-a follow-up report and analysis of factors influencing response to therapy. $N$ Engl J Med 1975; 293:378-83.

6 Maton PM, Murphy GM, Dowling RH. Ursodeoxycholic acid treatment of gallstones. Dose response study and possible mechanism of action. Lancet 1977; 2:1297-301.

7 Maudgal DP, Bird R, Northfield TC. Optimal timing of doses of chenic acid in patients with gallstones. $\mathrm{Br} \mathrm{Med} J$ $1979 ; 1: 922-3$.

8 Maudgal DP, Bird R, Blackwood WS et al. Low cholesterol diet: Enhancement of effect of CDCA in patients with gallstones. $\mathrm{Br}$ Med $J$ 1978; 2:851-3.

9 Mok HYI, Bell GD, Dowling RH. Effect of different doses of chenodeoxycholic acid on bile lipid composition and on side effects in patients with gallstones. Lancet $1974 ; 11: 253-7$.

10 Talalay P. Enzymatic analysis of steroid hormones. In: Glick D, ed. Methods of biochemical analysis. New York: Interscience, 1960: 8:119. 
11 Admirand WH, Small DM. The physicochemical basis of cholesterol gallstone formation in man. J Clin Invest 1968; 47:1043-52.

12 Bartlett GR. Phosphorus assay in column chromatography. J Biol Chem 1959; 234:466-8.

13 Roda A, Festi D, Sama C et al. Enzymatic determination of cholesterol in bile. Clin Chim Acta $1975 ; 64: 337-49$.

14 Thomas PJ, Hofmann AF. A simple calculation of lithogenic index of bile. Experimental biliary lipid composition on rectangular coordinates. Gastroenterology 1973; 65:698-700.

15 Hegardt FS, Dam H. The solubility of cholesterol in aqueous solution of bile salts and lecithin. $Z$ Ernaehrungswiss 1971; 10:223-33.

16 Holzbach RT, Marsh M, Olszewski M et al. Cholesterol solubility in bile: evidence that supersaturated bile is frequent in healthy man. J Clin Invest 1973; 52:1467-79. 